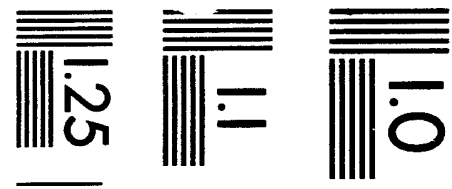

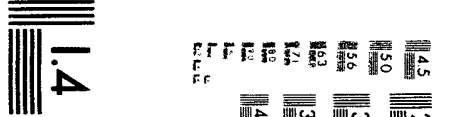

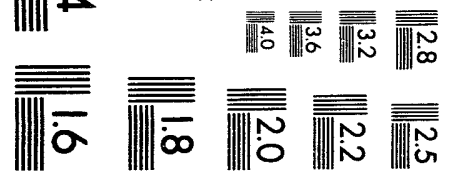



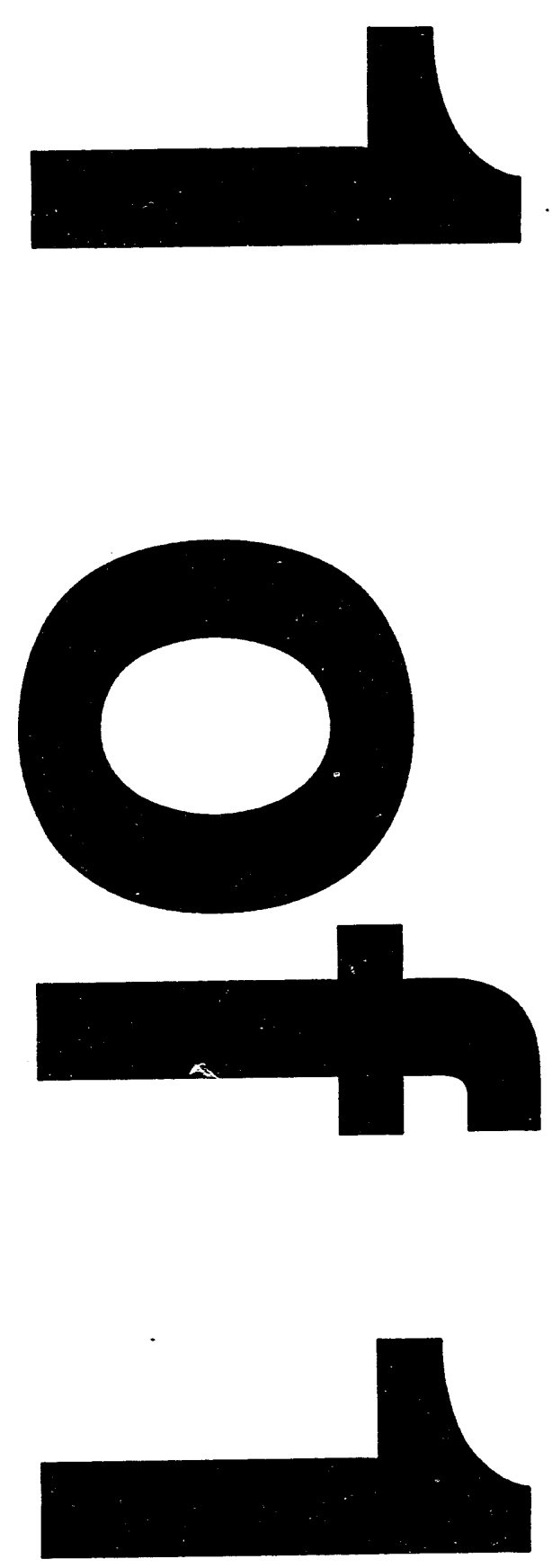


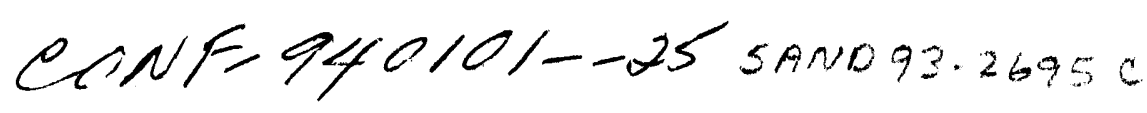

Log Nr. 174

\title{
CHARACTERISTICS AND CONTROL RESPONSE OF THE TOPAZ II REACTOR SYSTEM REAL-TIME DYNAMIC SIMULATOR
}

\author{
Kwan S. Kwok \\ Sandia National Laboratories \\ P.O. Box 5800 \\ Albuquerque, NM 87185-1176 \\ (505) 272-7326
}

CAIMERA READY MANUSCRIPT prepared for:

Eleventh Symposium

on Space Nuclear Power and Propulsion

Albuquerque, New Mexico

9-13 January 1994

initial submission: 19 July 1993

final submission: 12 November 1993

Author to whom correspondence should be sent:

Dr. Kwan S. Kwok

Sandia National Laboratories

Department 6474

P.O. Box 5800

Albuquerque, NM 87185-1176

(505) 272-7326

Fax (505) 272-7297

\section{DISCLAIMER}

\begin{abstract}
This report was prepared as an account of work sponsored by an agency of the United States Government. Neither the United States Government nor any agency thereof, nor any of their employees, makes any warranty, express or implied, or assumes any legal liability or responsibility for the accuracy, completeness, or usefulness of any information, apparatus, product, or process disclosed, or represents that its use would not infringe privately owned rights. Reference herein to any specific commercial product, process, or service by trade name, trademark, manufacturer, or otherwise does not necessarily constitute or imply its endorsement, recommendation, or favoring by the United States Government or any agency thereof. The views and opinions of authors expressed herein do not necessarily state or reflect those of the United States Government or any agency thereof.
\end{abstract}




\title{
CHARACTERISTICS AND CONTROL RESPONSE OF THE TOPAZ II REACTOR SYSTEM REAL-TIME DYNAMIC SIMULATOR
}

\author{
Kwan S. Kwok \\ Sandia National Laboratories \\ P.O. Box 5800 \\ Albuquerque, NM 87185-1176 \\ (505) 272-7326
}

\begin{abstract}
A dynamic simulator of the TOPAZ II reactor system has been developed for the Nuclear Electric Propulsion Space Test Program. The simulator combines first-principle modeling and empirical correlations in its algorithm to attain the modeling accuracy and computational through-put that are required for real-time execution. The overall execution time of the simulator for each time step is $15 \mathrm{~ms}$ when no data is written to the disk, and $18 \mathrm{~ms}$ when nine double precision data points are written to the disk once in every time step. The simulation program has been tested and it is able to handle a step decrease of $\$ 8$ worth of reactivity. It also provides simulations of fuel, emitter, collector, stainless steel, and $\mathrm{ZrH}$ moderator failures. Presented in this paper are the models used in the calculations, a sample simulation session, and a discussion of the performance and limitations of the simulator. The simulator has been found to provide realistic real-time dynamic response of the TOPAZ II reactor system under both normal and casualty conditions.
\end{abstract}

\section{INTRODUCTION}

A dynamic simulator of the TOPAZ II reactor system has been designed, constructed, and tested for the Nuclear Electric Propulsion (NEP) Space Test Program (Kwok 1994). The TOPAZ II Reactor System Real-time Dynamic Simulator is designed primarily for use as a test system for the development and qualification of the TOPAZ II Reactor Control Unit (RCU). It combines first-principle modeling and empirical correlations in its algorithm to attain the modeling accuracy and computational through-put that are required for real-time execution (Kwok 1953). In addition to being a test system for the RCU, it serves as a training tool for both TOPAZ. II operators and contrel system designers by providing users with hands-on experience that simulates the actual dynamic response of the TOPAZ II power system. The strong feedback mechanisms inherent in the TOPÁZ II design ar: apparent during a simulation session. Additionally, the simulator can be put under severe operating concitions, which may otherwise be impossible or extremely difficult to perform in a mock-up or pre-operational test in which hardware is involved. Examples are a continuous drum withdrawal or an ejection of the reflector while operating at fill power.

This paper discusses the modeling and characteristics of the TOPAZ II Reactor jystem Pal time Dynamic Simulator. First, the paper provides a description of the models empioyed in the arrulatur. The neutronic model includes a section on the treatment of the neutron source strength at shuldown. Slso inclidicd are the kinetics

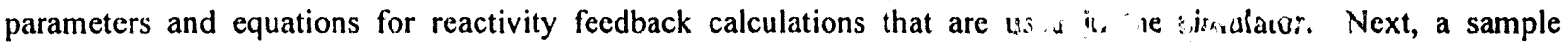
simulation session is given, in which major events for observation, profes th pigitis in reacior control, and

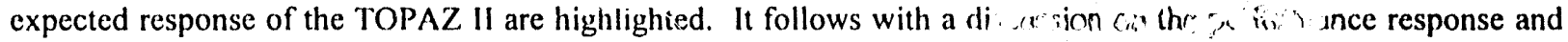
limitations of the simulator.

\section{MODELS}

The TOPAZ II power system employs a small and compact core, in which n w ins responses of the reactor are tightly coupled. The neutron flux shape of a tightly coupled reactor do s. The changes that occur in the reactor may be described by treating the entire is . a fioint."

\section{Point Kinetics Model}

The neutronic model is a space independent point kinetics model with a distributed neutron source. The equations describing the response of the reactor are (Henry 1975): 
$\frac{\mathrm{dT}(\mathrm{t})}{\mathrm{dt}}=\frac{(\rho(\mathrm{t})-\bar{\beta})}{\ell^{*}} \mathrm{~T}(\mathrm{t})+\sum_{\mathrm{i}=1}^{\mathrm{N}} \lambda_{i} \mathrm{C}_{\mathrm{i}}(\mathrm{t})+\mathrm{Q}(\mathrm{t})$, and

$\frac{d C_{i}(t)}{d t}=\frac{\beta_{i}}{\ell^{*}} T(t)-\lambda_{i} C_{i}(t)$, for $i=1, N$

where $T(t)$ is the amplitude function and is a weighted integral of all neutrons present in the reactor. Other symbols are defined as:

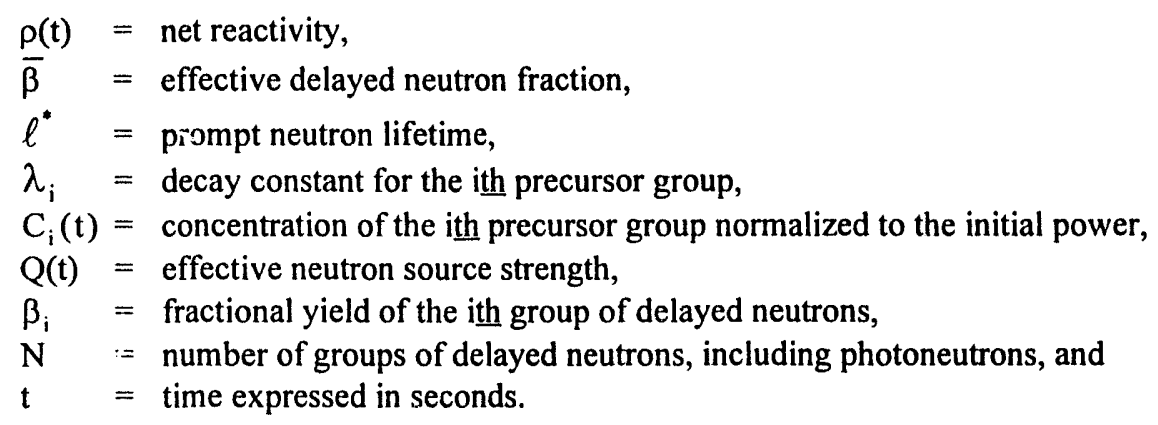

Six groups of delayed neutrons are used in the neutronic model. The effective delayed neutron fraction is 0.008 and the prompt neutron lifetime is $2 \times 10^{-5} \mathrm{~s}$. The respective kinetics parameters are shown in Table 1 (Glushkov 1993a).

TABLE 1. Reactor Kinetics Parameters.

\begin{tabular}{ll}
\hline Parameter & Value \\
\hline & \\
\hline Group 1 Delayed Neutron Fraction, $\beta_{1}$ & $3.040 \times 10^{-4}$ \\
Group 2 Delayed Neutron Fraction, $\beta_{2}$ & $1.704 \times 10^{-3}$ \\
Group 3 Delayed Neutron Fraction, $\beta_{3}$ & $1.504 \times 10^{-3}$ \\
Group 4 Delayed Neutron Fraction, $\beta_{4}$ & $3.256 \times 10^{-3}$ \\
Group 5 Delayed Neutron Fraction, $\beta_{5}$ & $1.024 \times 10^{-3}$ \\
Group 6 Delayed Neutron Fraction, $\beta_{6}$ & $2.080 \times 10^{-4}$ \\
Group 1 Delayed Neutron Precursor Decay Constant, $\lambda_{1}\left[\mathrm{~s}^{-1}\right]$ & 0.0127 \\
Group 2 Delayed Neutron Precursor Decay Constant, $\lambda_{2}\left[\mathrm{~s}^{-1}\right]$ & 0.0317 \\
Group 3 Delayed Neutron Precursor Decay Constant, $\lambda_{3}\left[\mathrm{~s}^{-1}\right]$ & 0.1160 \\
Group 4 Delayed Neutron Precursor Decay Constant, $\lambda_{4}\left[\mathrm{~s}^{-1}\right]$ & 0.3110 \\
Group 5 Delayed Neutron Precursor Decay Constant, $\lambda_{5}\left[\mathrm{~s}^{-1}\right]$ & 1.3970 \\
Group 6 Delayed Neutron Precursor Decay Constant, $\lambda_{6}\left[\mathrm{~s}^{-1}\right]$ & 3.8720 \\
\hline
\end{tabular}

Integral worth of the control drums in $\Delta \mathrm{K} / \mathrm{K}$ is given by the following equation (Glushkov 1993b):

$$
\begin{aligned}
& \rho(\theta)=6.89 \times 10^{-13} \theta^{5}-2.33 \times 10^{-10} \theta^{4}+3.28 \times 10^{-9} \theta^{3}+4.57 \times 10^{-6} \theta^{2}-5.88 \times 10^{-5} \theta+1.74 \times 10^{-4} \\
& \quad \text { where: }
\end{aligned}
$$

$\rho(\theta)=$ integral reactivity worth of the nine control drums, and

$\theta=$ angular position of the main control drum expressed in degrees.

The model first determines the change in reactivity caused by the change in position of the safety drums, control drums, and the radial reflector. It then combines this reactivity change with reactivity feedback caused by the temperature changes that occur in the moderator, reflector, core plates, $\mathrm{UO}_{2}$ fuel, and TFE electrodes. 


\section{Shutdown Neutron Source Strength}

The shutdown neutron source ievel is a direct result of spontaneous fission. These source neutrons will undergo subcritical multiplication and will reach a steady-state level in the reactor. The power level at shutdown depends on the number of source neutrons from spontaneous fission and the shutdown reactivity of the reactor. Equations (1) and (2) can be solved for the steady-state condition at shutdown by setting the $\mathrm{d} / \mathrm{dt}$ terms to zero and solving for the source term.

The Nuclear Engineering Handbook lists the rate of spontaneous fission for U-235 as $3.1 \times 10^{-4}$ fissions $/ \mathrm{g} / \mathrm{s}$ (Etherington 1958). The TOPAZ II reactor may have a fuel loading as high as $27 \mathrm{~kg}$ of U-235, which results in a neutron source strength of 8.37 fissions/s. The shutdown reactivity of the TOPAZ II is $-\$ 6.21$, which corresponds to a shutdown $\mathrm{K}_{\mathrm{eff}}$ of 0.95267 . The steady-state neutron population caused by subcritial multiplication further increases the source level to a fission rate of 177 fissions $/ \mathrm{s}$ at shutdown. There are about $3 \times 10^{10} \mathrm{fissions} / \mathrm{s} / \mathrm{W}$ (Henry 1975). This gives $6 \mathrm{nIV}$ as the shutdown power level, which corresponds to an effective neutron source level of $1.46 \times 10^{-5} \mathrm{~W} / \mathrm{s}$. This shutdown source strength is used in the evaluation of Equation (1) during execution of the simulation program.

\section{Reactivity Feedback}

Reactivity feedback caused by temperature changes in the $\mathrm{ZrH}$ moderator, Be reflector, reactor core support plates, $\mathrm{UO}_{2}$ fuel, and TFE electrodes has been determined under isothermal conditions up to a temperature of $1000 \mathrm{~K}$ (Gunther 1990). Linear extrapolation is used on the correlation for the $\mathrm{UO}_{2}$ fuel because the temperature in the fuel exceeds $1000 \mathrm{~K}$ during normal operation (El-Genk et al.1993). The following are mathematical expressions for reactivity feedback effects as a function of temperature in the moderator, reflector, TFE electrodes, core support plates, and fuel (Gunther 1990):

\section{Zirconium-Hydride Moderator:}

$$
\begin{aligned}
\Delta \rho_{\mathrm{m}}(\Delta \mathrm{K} / \mathrm{K})= & \left(\mathrm{T}_{\mathrm{m}}-\mathrm{T}_{0}\right)\left[-8.22 \times 10^{-16}\left(\mathrm{~T}_{\mathrm{m}}-\mathrm{T}_{0}\right)^{4}+1.60 \times 10^{-12}\left(\mathrm{~T}_{\mathrm{m}}-\mathrm{T}_{0}\right)^{3}\right. \\
& \left.-1.11 \times 10^{-9}\left(\mathrm{~T}_{\mathrm{m}}-\mathrm{T}_{0}\right)^{2}+2.92 \times 10^{-7}\left(\mathrm{~T}_{\mathrm{m}}-\mathrm{T}_{0}\right)+1.76 \times 10^{-5}\right]
\end{aligned}
$$

where:

$$
\begin{array}{ll}
\Delta \rho_{\mathrm{m}}(\Delta \mathrm{K} / \mathrm{K}) & =\text { change of reactivity in the moderator in } \Delta \mathrm{K} / \mathrm{K}, \\
\mathrm{T}_{\mathrm{m}} & =\text { temperature of the moderator, and } \\
\mathrm{T}_{0} & =\text { initial temperature of the moderator, given as } 300 \mathrm{~K} .
\end{array}
$$

$\underline{\text { UO }}_{2}$ Fuel:

$\Delta \rho_{\mathrm{f}}(\Delta \mathrm{K} / \mathrm{K})=1.2 \times 10^{5}\left(\mathrm{~T}_{\mathrm{f}}-\mathrm{T}_{0}\right)-1.38 \times 10^{-2}\left\{\left(\frac{\mathrm{T}_{\mathrm{f}}}{\mathrm{T}_{0}}\right)^{\frac{1}{2}}-1\right\}$, for $\mathrm{T}_{\mathrm{f}}<800 \mathrm{~K}$,

and

$\Delta \rho_{\mathrm{f}}(\Delta \mathrm{K} / \mathrm{K})=-1 \times 10^{-3}-2.2 \times 10^{-4}\left(\mathrm{~T}_{\mathrm{f}}-\mathrm{T}_{0}\right)$, for $\mathrm{T}_{\mathrm{f}}>800 \mathrm{~K}$,

where:

$$
\begin{array}{ll}
\Delta \rho_{\mathrm{r}}(\Delta \mathrm{K} / \mathrm{K}) & =\text { change of reactivity in the } \mathrm{UO}_{2} \text { fuel in } \Delta \mathrm{K} / \mathrm{K}, \\
\mathrm{T}_{\mathrm{f}} & =\text { temperature of the } \mathrm{UO}_{2} \text { fuel, and } \\
\mathrm{T}_{0} & =\text { initial temperature of the } \mathrm{UO}_{2} \text { fuel, given as } 300 \mathrm{~K} .
\end{array}
$$

Beryllium Reflector:

$$
\Delta \rho_{r}(\Delta K / K)=3.8 \times 10^{-3}\left\{1-\left(\frac{T_{0}}{T_{r}}\right)^{2}\right\}
$$

where: 


$$
\begin{array}{ll}
\Delta \rho_{\mathrm{r}}(\Delta \mathrm{K} / \mathrm{K}) & =\text { change of reactivity in the reflector in } \Delta \mathrm{K} / \mathrm{K}, \\
\mathrm{T}_{\mathrm{r}} & =\text { temperature of the reflector, and } \\
\mathrm{T}_{0} & =\text { initial temperature of the reflector, given as } 300 \mathrm{~K} .
\end{array}
$$

\section{Core Support Plates:}

$$
\Delta \rho_{c p}(\Delta K / K)=-2.22 \times 10^{-6}\left(T_{c p}-T_{0}\right)
$$

where:

$$
\begin{array}{ll}
\Delta \rho_{\mathrm{cp}}(\Delta \mathrm{K} / \mathrm{K}) & =\text { change of reactivity in the core support plates in } \Delta \mathrm{K} / \mathrm{K}, \\
\mathrm{T}_{\mathrm{cp}} & =\text { temperature of the core support plates, and } \\
\mathrm{T}_{0} & =\text { initial temperature of the core support plates, given as } 300 \mathrm{~K} .
\end{array}
$$

\section{TFE Electrodes:}

$\Delta \rho_{\mathrm{e}}(\Delta \mathrm{K} / \mathrm{K})=8.52 \times 10^{-4}-4.26 \times 10^{-4}\left\{\left(\frac{\mathrm{T}_{\mathrm{c}}}{\mathrm{T}_{0}}\right)^{\frac{1}{2}}+\left(\frac{\mathrm{T}_{\mathrm{c}}}{\mathrm{T}_{0}}\right)^{\frac{1}{2}}\right\}$

where:

$$
\begin{array}{ll}
\Delta \rho_{e}(\Delta \mathrm{K} / \mathrm{K}) & =\text { change of reactivity in the TFE electrodes in } \Delta \mathrm{K} / \mathrm{K}, \\
\mathrm{T}_{\mathrm{e}} & =\text { temperature of the emitter, } \\
\mathrm{T}_{\mathrm{c}} & =\text { temperature of the collector, and } \\
\mathrm{T}_{0} & =\text { initial temperature of the TFE electrodes, given as } 300 \mathrm{~K} .
\end{array}
$$

\section{Thermal Models}

Thermal systems in the TOPAZ II reactor power system closely follow a typical response of a first order dynamic system. Review of the data taken during the Thermionic System Evaluation Test (TSET) shows that each thermal system exhibits an equivalent time constant and an asymptotic final value. This kind of behavior is also noted in the development of the Thermionic Transient Analysis Model (TITAM) at the University of New Mexico (El-Genk et al. 1993).

Each thermal model has a final temperature that is directly proportional to the reactor power. This is the asymptotic value that the system will approach after four or more time constants. Using results from both TSET and TITAM, a time constant that determines the overall system response is calculated. Both the time constant and the final temperature can be fine-tuned to calibrate the system response, if so desired.

Under casualty conditions, high temperatures may cause structural failures in the systems. The thermal models in the simulator monitor critical components for excessively high temperatures. These critical components are 1) the $\mathrm{UO}_{2}$ fuel, 2) the molybdenum emitter, 3) the molybdenum collector, 4) the stainless steel in the primary coolant system, and 5) the reflector. A warning message will be displayed on the screen if the temperature in any of these components equals or exceeds the respective melting temperature.

\section{SAMPLE SIMULATION SESSION}

In an actual startup of the TOPAZ II power system, there are many neutronic, thermal, mechanical, and electrical limits that must be observed The simulator models the important events and provides warning messages if temperature limits are exceeded.

A typical reactor startup for the TOPAZ II power system begins with withdrawing the safety drums one at a time. The user should allow sufficient time between the withdrawal of each safety drum in order for subcritical multiplication to take place. Build-up of subcritical neutrons can be observed by monitoring the rate of increase of the reactor power level. The control drums are then withdrawn in a step-wise manner until the main drum reaches $154^{\circ}$. Again, the step-wise approach is used to allow a sufficient neutron population to build up as a result of a source in a subcritical reactor prior to attaining criticality. This is important for proper operation of the nuclear instrumentation at source levels. The operator will test whether the reactor is critical during the step-wise withdrawal of the control drums, by observing the "prompt" and "delayed" responses of the reactor during and after the drum movement. The reactor is critical when a steady period (a spontaneous exponential increase) is maintained 
following the initial prompt effects caused by drum motions. Once the reactor is critical, the control drums are driven inward to $145^{\circ}$ and held there. When the power reaches the point of adding heat, approximately $5 \mathrm{~kW}$, the operator should limit the power increase at a rate of no more than $600 \mathrm{~W} / \mathrm{s}$ until $35 \mathrm{~kW}$. The thermal covers should be ejected shortly after passing this point. The rate of power increase should be decreased to no more than $80 \mathrm{~W} / \mathrm{s}$ after $35 \mathrm{~kW}$. When the power approaches the desired level, $115 \mathrm{~kW}$, the control drums should be carefully adjusted to maintain a steady power level. At this time, particular attention must be paid to the overall positive feedback mechanisms inherent in the TOPAZ II power system. The operator must constantly adjust the control drums inward to counteract the positive reactivity caused by the temperature increase in the moderator and the reflector. At this point, the operator can set and engage the automatic controller. A good set of numbers to use is to set the gain multiplier at $5, \mathrm{P}$ at or near $4, \mathrm{I}$ at or near 0.2 , and $\mathrm{D}$ at or near 0.1 . This allows a fairly high gain for proportional adjustment, a somewhat small integral compensation for prolonged lagging effects, and a small compensation based on the rate of change of the error. The operator can now "vent" the cesium and increase the work section output of the thermionic system by pushing a button. Once the thermionic system output is stabilized and the proper EM pump voltage has been verified, the startup battery electrolyte should be vented. The EM pump voltage can be monitored on channel 10 of the analog output boards.

The automatic controller will regulate the reactor power at the set point, while the temperature changes in the different systems cause reactivity effects in the reactor. The control drums will eventually be driven to about $90^{\circ}$ after the reactor system as a whole reaches thermal equilibrium.

A final evolution the operator can simulate is that of a reflector ejection. This will shut down and change the state of the reactor to below the initial shutdown condition. The onerator initiates the reflector ejection by pushing the REFLECTOR RELEASE 1 and REFLECTOR RELEASE 2 buttons. The operator will observe an initial prompt drop caused by the elimination of the short-lived prompt neutrons. This factor of 50 decrease will occur instantaneously, followed by a rapid decrease to a factor of 100 below the initial power level in a matter of seconds. This is followed by a classical decrease of the reactor power, limited by the rate of decay of the longest delayedneutron precursor group that has a half-life of 55 seconds. The resultant reactor period is $-80 \mathrm{~s}$. The operator can easily observe this by using a stop watch to confirm that the time it takes the reactor power to decrease by a factor of 2.7 is indeed $80 \mathrm{~s}$.

\section{PERFORMANCE AND LIMITATIONS}

The overall execution time of the simulator for each time step is $15 \mathrm{~ms}$ when no data is being written to the disk, and $18 \mathrm{~ms}$ when nine double precision data points are written to the disk once every time step. If necessary, execution time can be further improved by updating the screen and writing to the disk at a frequency less than once every time step.

In each time step, neutronic integration is performed with an integration time step size of $0.5 \mathrm{~ms}$. Convergence is usually accomplished in about 20 iterations. This combination of integration time step size and number of integration steps is optimized for an average cycle time of $20 \mathrm{~ms}$ or less. However, for more severe transients, numerical instabilities can be avoided by decreasing the integration time step size, while proportionally increasing the number of integration steps. For example, a $0.1 \mathrm{~ms}$ integration tine step size is used with 100 integration steps. Finer integration time step size may be applicable if the average time step size were decreased through reduction of screen update frequency.

During a simulation session of a reactor startup and steady-state operation, the simulator depicts the effects of prompt and delayed neutrons correctly. That is, when control drum motions are initiated, the neutron power increase will be dominated by the prompt neutron life time when drum motion is present. The initial surge of prompt neutrons will eventually cease, once drum motion has stopped, and the delayed neutron precursor concentrations come to an equilibrium.

When the reactor power is above the point of adding heat, the simulator properly introduces reactivity feedback caused by the heating up of the moderator, reflector, fuel, electrodes, and core plates. The strong positive delayed effect of the moderator is evident when the control drums are "turned in" at a substantial rate in order to compensate for the positive temperature feedback. The control drums are initially at about $130^{\circ}$ when the reactor reaches criticality. The drums are normally shimmed to about $90^{\circ}$ when the reactor reaches thermal equilibrium. 
The neutronics calculation in the simulator is based on first principle, whereas the thermal models and the thermionics model are based on empirical correlations. Recalibration of these dynamic models should be performed when new data becomes available. The neutronic calculations are integrated with a time step size of $.5 \mathrm{~ms}$. Numerical instabilities may be experienced if excessive reactivity is inserted in one step. The simulation program has been tested and it is able to handle a step decrease of $\$ 8$ worth of reactivity.

Reactivity worth of the control drums and safety drums exhibit effects caused by shadowing. The simulator now handles this non-linear effect by reducing the worth of each safety drum from $\$ 0.67$ to $\$ 0.50$. This is the reason for a possible very slow startup with one safety drum fully inserted.

The model of the control drums does not include the gear back-lash effect (Luppov et al.1993). The effect was estimated to be small; however, it requires six to eight seconds for the effect to vanish. This time lag may be important to the overall dynamic response of the TOPAZ II. It should be investigated and a sensitivity study performed on the simulator.

\section{CONCLUSIONS}

The TOPAZ II Reactor System Real-time Dynamic Simulator has been completed in accordance with the design requirements developed for supporting the RCU development effort, and has provided realistic simulation of the dynamic response of the TOPAZ II reactor system. The overall execution time of the simulator for each time step is $15 \mathrm{~ms}$ when no data is written to the disk, and $18 \mathrm{~ms}$ when nine double precision data points are written to the disk once in every time step. The simulation program has been tested and it is able to handle a step decrease of $\$ 8$ worth of reactivity. It also provides simulations of fuel, emitter, collector, stainless steel, and $\mathrm{ZrH}$ moderator failures.

Although the simulator has been developed primarily to facilitate the development and qualification of the RCU, manual control of the simulator has provided TOPAZ operators, control system designers, and model developers significant insight into the control characteristics of the TOPAZ II reactor system.

\section{Acknowledgments}

This work was funded by the Ballistic Missile Defense Organization. The author performed this work for the Air Force Philips Laboratory, representing Sandia National Laboratories, which is operated by the U.S. Department of Energy under contract DE-AC04-94AL85000. The views expressed in this paper are those of the author and do not reflect the official policy or position of the U.S. Air Force, Department of Defense, or the U.S. Government.

\section{References}

El-Genk, M.S., H. Xue, and D. Paramonov (1993) "Start-up Simulation of a Thermionic Space Nuclear Reactor System," in Proceedings of the 10th Symposium on Space Nuclear Power Systems, CONF-930103, M.S. El-Genk and M.D. Hoover, eds., American Institute of Physics, New York, NY.

Etherington, H. ed. (1958) Nuclear Engineering Handbook, McGraw-Hill Book Co., New York., NY 1958.

Glushkov, E.C. (1993a) Personal Communications, INERTEK, Moscow, Russia, February 1993.

Glushkov, E.C. (1993b) Personal Communications, New Mexico Engineering Research Institute, Albuquerque, NM, June 1993.

Gunther, N.G. (1990) Characteristics of the Soviet TOPAZ II Space Power System, Report SPI-52-1, Space Power Inc., San Jose, CA.

Henry, A.F. (1975) Nuclear Reactor Analysis, MIT Press, Cambridge, MA 1975.

Kwok, K.S. (1993) TOPAZ II Reactor System Real-time Dynamic Simulator - User's Guide and Reference Manual, SAND93-2725, Sandia National Laboratories, Albuquerque, NM, in preparation.

Kwok, K.S. (1994) "Design and Construction of the TOPAZ II Reactor System Real-time Dynamic Simulator," Proceedings of the Ilth Symposium on Space Nuclear Power Systems, CONF-94101, M.S. El-Genk ed., American Institute of Physics, New York.

Luppov, A.N., K.N. Prikot, G.A. Lisochkin, V.V. Skorlygin, and K.S. Kwok (1994) "Control Drum Drive Mechanism and Regulation Characteristics of the TOPAZ II Reactor," Proceedings of the 1/th Symposium on Space Nuclear Power Systems, CONF-94101, M.S. El-Genk ed., American Institute of Physics, New York. 

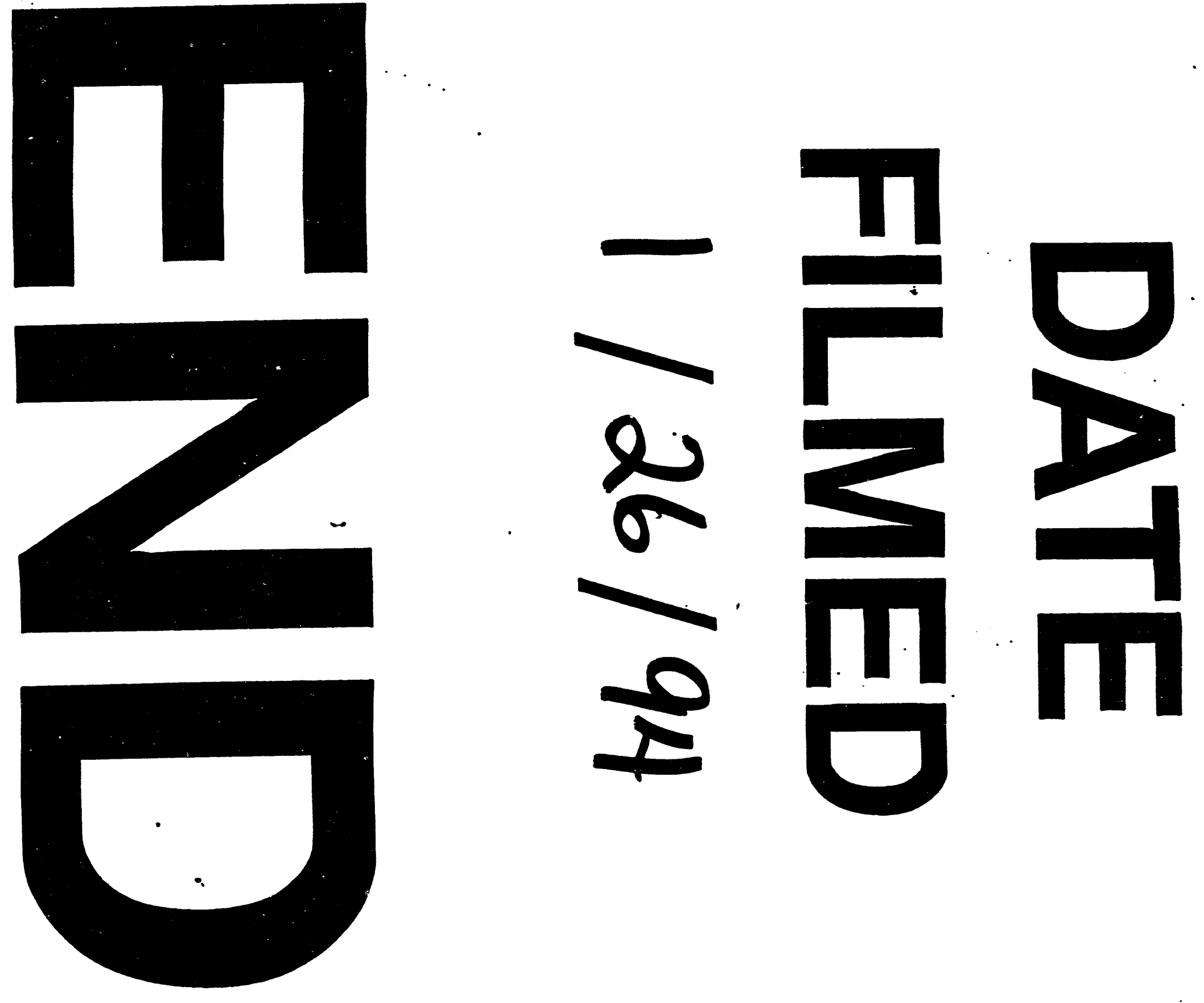


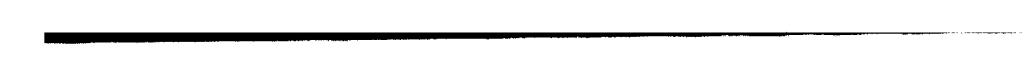

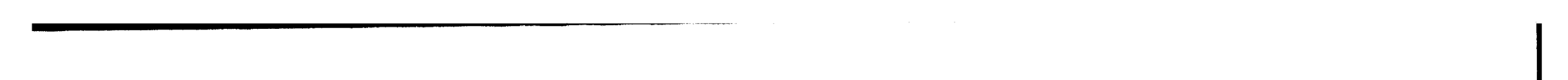

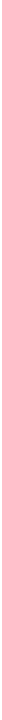

